

\title{
Adjusted-Program-Budget Marginal-Analysis for Student Development Activity Planning and Budget Allocation
}

\author{
Bilkisu Maijama’a and Engku M. Nazri \\ School of Quantitative Sciences, Universiti Utara Malaysia, 06010 UUM Sintok, Kedah, Malaysia \\ Corresponding Author Email: enazri@uum.email.com
}

\begin{abstract}
Setting priorities and making decisions on allocation and reallocation of university resources based on the direction of the university as translated in its strategic plan must be executed with transparency and accountability and will be of great importance. It is becoming even more crucial, particularly for universities in Malaysia with the recent budget cut imposed by the Malaysian government. In this paper, we proposed an implementation of Program-Budget Marginal-Analysis (PBMA) which is currently being employed for strategic budget planning in the health industry to be applied for the university strategic budget plan as part of the overall strategic planning process. Firstly, the similarities between the steps in PBMA with the steps involved in planning and executing the university strategic plan were studied. Next, the existing PBMA was adjusted and modeled to suit the needs of the steps involved in selecting and allocating budget for the students of UABC's 2017 development activities. The outcome of this implementation using 0-1 integer programming model showed that the targeted achievements could be realized within the allocated budget that was provided by the university. This adjusted-PBMA will be useful and suitable to be implemented by organizations with key performance indicator-oriented programs and having limited budget allocation issues.
\end{abstract}

Keywords: Adjusted-PBMA, student-activity planning, university budget allocation, 0-1 IP.

\section{Introduction}

Program-Budget Marginal-Analysis (PBMA) is a single decision making point tool used for organizations to make decisions on whether to fund or not to fund certain programs or activities by articulating high performance success in terms of value for money [1]. The main goal of applying PBMA is to answer the question of whether or not more needs can be included within existing resources, through the process of prioritization about cost. Thus, decision makers need to look at the availability of resources to fund available programs to produce adequate benefit. It is not an easy task since some programs with high funding have to be forfeited for existing lower value programs producing high benefit services with minimal cost [2].

Originated in the 1950s in the USA Rand Cooperation, and with major application in the defense department in the 1960s, PBMA was at the time, used as a cost-accounting tool to display overtime, deployment of resources for different military objectives, and in allocating additional missiles to destroy military targets [3]. Later, for decades, Alain Einthoven, a researcher on PBMA bridged the gap between military and health care applications in the USA to maximize health gain by deploying available resources for greater benefit [4]. Nowadays, PBMA is also being applied for decision making in the government funding of research, guidelines for clinicians, as well as pricing decisions by manufacturers and government [5].

Mitton, Dionne, and Donaldson in [6] outlined seven steps for PBMA:
1. Determining the goal, aim and scope of setting the program.

2. Identifying the available resources for funding a particular program, that is the program budget.

3. Conducting marginal analysis by taking the viewpoints of stakeholders, managers, service oviders, consumers, and head of organizations in setting priorities.

4. Determining the decision making criteria to be used to maximize benefits or profits as well as minimization of cost.

5. Identifying the options in the program for which choices are to be made. Evaluating the potential impact of investment and disinvestment in terms of benefit and cost.

6. Validating the outcome and the decision made in the process of allocation and reallocation of funds according to the ratio of cost-benefit.

Based on the seven steps outlined above, there is a possibility that PBMA can also be applied in the context of financing the management of universities, particularly in Malaysia whereby with the recent budget cut and the pressure to move the universities' reputation by improving their ranking, the burden of managing the available funding resources becomes more crucial.

\section{Background}

One popular measure used by universities to improve the performance of the institutions is through a proper strategic plan. A strategic plan designed by different universities is used as a guide and key indicator of progress in assessing the university and 
equipping the university with challenges and realities of the educational needs in this millennium [7]. Unfortunately, some universities set up their specific strategies without consideration to the limited available resources where less attention is channeled to the cost in achieving the best performance, which may later lead to mismanagement of funds allocated in such universities. At one of the universities in Malaysia (to be referred later as U-ABC), for example, the process of developing the strategic plan is as follows:

Step 1: The top management team decides on the main thrusts for the strategic plan.

Step 2: The faculty deans and other management team members elaborate on the specific strategies along with the key performance indicators (KPIs) under each main thrust.

Step 3: The strategic planning office distributes the strategies and KPIs to the respective schools, units and student body.

Step 4: The bursar office allocates the budget to each school, unit, and student body.

Step 5: Each school, unit, and student body plans and executes suitable activities to achieve the KPIs given.

The problem occurs when there is a change in policy (coming from the university itself or from other stakeholders), or a change in the university management team. Normally, with these two changes, the strategic plan will also change.

New strategies will be introduced and as a result new activities will be suggested for implementation, thus raising these three basic questions:

1. Should the new strategies and activities be included on top of the existing strategies and activities?

2. How to decide and finalize the strategies and activities to be implemented?

3. How should the budget be allocated to ensure that all the KPIs can be realized?

Since the steps involved in PBMA are somewhat useful in designing the strategic plan for a university, particularly in the selecting of activities and the allocation of budget for those activities, the objective of this research was therefore to apply PBMA, with some adjustments if required, to select and allocate suitable budget for the strategies and activities to be implemented. For the purpose of illustration, the scope was confined to the selection and budget allocation for the student development activities which are being assigned to be planned and monitored by the student body. A case study at U-ABC would be illustrated.

The selection of these student development activities and the allocation of suitable budget to each activity via PBMA was executed by:

1. Identifying the similarities between the steps in PBMA with the steps involved in planning and executing the university strategic plan.

2. Adjusting the steps in PBMA to suit the needs of the steps involved in planning and budgeting of the strategies and KPIs in the university strategic plan.

3. Modeling the adjusted-PBMA steps for planning and budgeting of the strategies and KPIs in the university strategic plan.

4. Implementing the adjusted-PBMA steps for planning and budgeting of the strategies and KPIs in the university strategic plan.

\section{Methodology}

As elaborated in Section I, the framework for implementing PBMA can be summarized as follows [6]:

1. Identify the total amount of available resources or funding allocated to activities.

2. Examine the way the resources are currently allocated to activities. Are there any prioritization exercise conducted in deciding the amount of resources to be allocated?
3. Evaluate the benefit of cost of expansions with regards to the new activities suggested for the next period of action.

4. In any of the existing services in use, identify the more effective service with fewer resources to disallow other items from being included.

5. Determine various alternatives to be reallocated with fewer resources for more effectiveness about cost than any items on the priority setting list.

In the case of the U-ABC's student development's activity planning and budgeting, the adoption of PBMA process was as follows:

Firstly, the total budget allocated by the university management for student development activities in 2017 to be planned and monitored by the student body is RM50,000.00, which is lower than the total budget allocated for 2016. Secondly, the amount allocated was based on the KPIs given to the student body as shown in Table 1 and deemed appropriate by the U-ABC's bursary office. It did not involve any further prioritization exercise. Therefore, thirdly, to apply PBMA, certain prioritization technique should be employed. One possible way is through economic evaluators.

When allocating and re-allocating funds, organizations require evidence of effectiveness of interventions with reasonable value for money [8]. As such, economic evaluators are needed to perform a comparative analysis or alternative of actions particularly with regards to consequences and cost in executing or implementing certain options. Failure to evaluate the cost effectiveness may lead to over expenditure or reduced services when improvements are actually possible with less expenses through the process of cost effectiveness.

Depending on the type of the analysis of the consequences, there are mainly five economic evaluators used for PBMA, namely, costbenefit analysis (CBA), cost-utility analysis (CUA), costeffectiveness analysis (CEA), cost-minimization analysis (CMA), and cost-consequences analysis (CCA) [1]. Although there are some major differences between these techniques, the basic formula used to determine the marginal contribution of programs or activities towards achieving the management objective is based on the amount of cost per unit effect [9]. Thus, for U-ABC's case, the formula used was based on the ratio of the amount of money spent on an activity and the point contribution set by any university ranking body such as SETARA, Times Higher Education World University Ranking, and Academic Ranking of World Universities, for that particular activity. An example of the rating point given per activity conducted (also used in this study) is given in Table 1 and the marginal cost contribution (MCC) formula used is:

$$
\begin{aligned}
& \text { MCC }=(\text { Amount needed per activity }) /(\text { Rating point } \\
& \text { obtained per activity })
\end{aligned}
$$

Meanwhile, based on the U-ABC's 2016 strategic plan report, the amount used by programs/activities in 2016 are as given in Table 2.

Table 1 KPIs for 2017 Student Development Activities to be Handled by the Student Body and the Respective Ranking Point

\begin{tabular}{|l|c|c|}
\hline \multicolumn{1}{|c|}{ Key Indicators } & $\begin{array}{c}\text { Total } \\
\text { Activities to } \\
\text { be Handled by } \\
\text { the Student } \\
\text { Body }\end{array}$ & $\begin{array}{c}\text { Points } \\
\text { Accumulated per } \\
\text { Activity for } \\
\text { Ranking }\end{array}$ \\
\hline $\begin{array}{l}\text { A. Number of festivals, concerts, } \\
\text { cultural and special events. }\end{array}$ & 2 & 0.1 \\
\hline B. Number of programs promoting \\
local culture.
\end{tabular}




\begin{tabular}{|c|c|c|}
\hline alumni and post graduates & & \\
\hline $\begin{array}{l}\text { E. Number of collaboration with Co- } \\
\text { operative and Entrepreneurship } \\
\text { Development Institute (CEDI), } \\
\text { Students Council and Students' } \\
\text { Associations. }\end{array}$ & 1 & 0.2 \\
\hline $\begin{array}{l}\text { F. Number of comprehensive global } \\
\text { exposure/engagement. }\end{array}$ & 2 & 0.3 \\
\hline $\begin{array}{l}\text { G. Number of employer engagement } \\
\text { sessions. }\end{array}$ & 2 & 0.2 \\
\hline H. Number of organized career fairs. & 1 & 0.2 \\
\hline
\end{tabular}

Table 2 List of 2016 Activities, Amount Used in 2016, and Expected Amount Needed for 2017

\begin{tabular}{|c|c|c|}
\hline $\begin{array}{c}\text { Activity } \\
(2016)\end{array}$ & Amount Used (RM) & $\begin{array}{c}\text { Expected Amount Needed for } \\
2017(\mathrm{RM})\end{array}$ \\
\hline $\mathrm{A} 1$ & $3,000.00$ & $3,300.00$ \\
\hline $\mathrm{A} 2$ & $3,700.00$ & $4,070.00$ \\
\hline $\mathrm{B} 1$ & $2,000.00$ & $2,200.00$ \\
\hline $\mathrm{B} 2$ & $2,200.00$ & $2,420.00$ \\
\hline $\mathrm{C} 1$ & $3,200.00$ & $3,520.00$ \\
\hline $\mathrm{C} 2$ & $1,800.00$ & $1,980.00$ \\
\hline $\mathrm{C} 3$ & $1,500.00$ & $1,650.00$ \\
\hline $\mathrm{C} 4$ & $2,400.00$ & $2,640.00$ \\
\hline C5 & $2,200.00$ & $2,420.00$ \\
\hline D1 & $4,900.00$ & $5,390.00$ \\
\hline E1 & $4,300.00$ & $4,730.00$ \\
\hline F1 & $10,400.00$ & $11,440.00$ \\
\hline F2 & $6,000.00$ & $6,600.00$ \\
\hline G1 & $2,900.00$ & $3,190.00$ \\
\hline G2 & $2,000.00$ & 2.200 .00 \\
\hline H1 & $8,000.00$ & $8,800.00$ \\
\hline Total & $\mathbf{6 0 , 5 0 0 . 0 0}$ & $\mathbf{6 6 , 5 5 0 . 0 0}$ \\
Amount & & \\
\hline
\end{tabular}

The same activities are suggested to be maintained for 2017 along with a few other new activities proposed by the members of the student body. With the increase in the cost of living, the amount needed for each activity is expected to increase by approximately 10 percent as shown in Table 2 . The new proposed activities are given in Table 3.

Table 3 New Proposed Activities and Amount Needed for 2017.

\begin{tabular}{|c|c|}
\hline New Activity & Expected Amount \\
\hline AA1 & $5,200.00$ \\
\hline BB1 & $2,900.00$ \\
\hline BB2 & $4,100.00$ \\
\hline CC1 & $1,500.00$ \\
\hline CC2 & $2,400.00$ \\
\hline DD1 1 & $3,900.00$ \\
\hline EE2 & $6,000.00$ \\
\hline EE3 & $7,500.00$ \\
\hline FF1 & $4,100.00$ \\
\hline GG1 & $9,000.00$ \\
\hline GG2 & $2,000.00$ \\
\hline HH1 & $3,200.00$ \\
\hline HH2 & $8,000.00$ \\
\hline up & $5,200.00$ \\
\hline
\end{tabular}

Fourthly, upon further investigation on the 2016 activities, it was found that some of the activities conducted could actually fulfil the KPI for more than 1 indicator. For example, activity H1 for key indicator $\mathrm{H}$ can also fulfil the KPI for key indicator G. Thus, before selecting and finalizing the activities to be conducted for 2017, activity-key indicator mapping was done. At the same time, the MCC-value using formula (1) for each activity was also calculated. The mapping and MCC-values are as given in Table 4.

Fifthly, and finally, having done the mapping and having calculated the MCC-value, the allocating and reallocating of activities or in this case, the final selection of activities to be conducted in 2017 along with the budget allocation process can be done. This was done using 0-1 integer programming model (0-1 IP).

0-1 IP is a mathematical technique applied in mathematical and computer modeling as well as simulations to find the best possible solution in planning, routing, scheduling, assigning, designing, and allocation of limited resources to achieve maximum benefit with minimum cost. In the case of planning and resource allocation, 0-1 ILP is used for priority setting to determine which set of activities, projects or strategies to be implemented based on certain constraints such as budget restriction, and some other special constraints, in order to maximize or minimize the intended objective [10].

Table 4 Activity-Key Indicator Mapping and MCC-Values

\begin{tabular}{|c|c|c|c|c|c|c|c|c|c|}
\hline \multirow{2}{*}{ Activity } & \multicolumn{8}{|c|}{ Key Indicator } & \multirow{2}{*}{ MCC } \\
\hline & $\mathrm{A}$ & $\mathrm{B}$ & $\mathrm{C}$ & $\mathrm{D}$ & $\mathrm{E}$ & $\mathrm{F}$ & G & $\mathrm{H}$ & \\
\hline A1 & 1 & 1 & & & & & & & 33,000 \\
\hline A2 & 1 & & & & & & & & 40,700 \\
\hline AA1 & 1 & & 1 & & & & & & 52,000 \\
\hline B1 & & 1 & 1 & & & & & & 22,000 \\
\hline B2 & & I & & & & & & & 24,200 \\
\hline BB1 & & I & 1 & & & & & & 29,000 \\
\hline BB2 & & 1 & & & & & & & 41,000 \\
\hline $\mathrm{C} 1$ & & & 1 & 1 & & & & & 35,200 \\
\hline $\mathrm{C} 2$ & & I & 1 & 1 & & & & & 19,080 \\
\hline $\mathrm{C} 3$ & & & 1 & & & & & & 16,500 \\
\hline $\mathrm{C} 4$ & & 1 & 1 & & & & & & 26,400 \\
\hline C5 & & & 1 & & & & & & 24,200 \\
\hline $\mathrm{CC} 1$ & & 1 & 1 & 1 & & & & & 15,000 \\
\hline $\mathrm{CC} 2$ & & 1 & 1 & & & & & & 24,000 \\
\hline D1 & & & & l & & & 1 & & 26,950 \\
\hline DD1 & & & & 1 & & & 1 & 1 & 19,500 \\
\hline E1 & & & & & 1 & & & & 23,650 \\
\hline EE1 & & & & & 1 & & 1 & 1 & 30,000 \\
\hline EE2 & & & & 1 & 1 & & & & 37,500 \\
\hline EE3 & & & & & 1 & & & & 20,500 \\
\hline $\mathrm{F} 1$ & & 1 & & & & 1 & & & 38,133 \\
\hline $\mathrm{F} 2$ & & 1 & & & & 1 & & & 22,000 \\
\hline FF1 & & 1 & & & & 1 & & & 30,000 \\
\hline G1 & & & & 1 & & & 1 & & 15,950 \\
\hline G2 & & & & & & & 1 & & 11,000 \\
\hline H1 & & & & 1 & & & 1 & & 40,000 \\
\hline HH1 & & & & & & & 1 & & 16,000 \\
\hline HH2 & & & & & 1 & & 1 & 1 & 44,000 \\
\hline
\end{tabular}

(Note: / indicates the activity can fulfil the key indicator)

The 0-1 IP model employed for the U-ABC problem was based on the following requirements:

1. Decision to be made: Which activities among the activities listed in Table 4 to be selected for implementation by the student body.

2. Objective function: To minimize the total cost needed to run all the activities selected. In this case, the objective can be translated as minimizing the MCC-value.

3. Constraints: Budget constraints as well as the minimum number of total activities to be planned for 2017.

Using the information in Table 1, Table 2, Table 3, and Table 4, the final 0-1 IP model is as follows:

Objective Function:

Min $M C C=33,000 A 1+40,700 A 2+52,000 A A 1+22,000 B 1+$ $24,200 B 2+29,000 B B 1+41,000 B B 2+35,200 C 1+19,800 C 2+$ $16,500 C 3+26,400 C 4+24,200 C 5+15,000 C C 1+24,000 C C 2+$ $26,950 D 1+19,500 D D 1+23,650 E 1+30,000 E E 1+37,500 E E 2+$ $20,500 E E 3+38,133 F 1+22,000 F 2+30,000 F F 1+15,950 G 1+$ $11,000 G 2+40,000 G G 1+16,000 G G 2+44,000 H 1+40,000 H H 1+$ 


\section{$26,000 \mathrm{HH} 2$}

Subject to

1. Budget constraint

$3,300 A 1+4,070 A 2+5,200 A A 1+2,200 B 1+2,420 B 2+2,900 B B 1+$ $4,100 B B 2+3,520 C 1+1,980 C 2+1,650 C 3+2,640 C 4+2,420 C 5+$ $1,500 C C 1+2,4,00 C C 2+5,390 D 1+3,900 D D 1+4,730 E 1+$ $6,000 E E 1+7,500 E E 2+4,100 E E 3+11,440 F 1+6,600 F 2+$ $9,000 F F 1+3,190 G 1+2,200 G 2+2,000 G G 1+3,200 G G 2+$ $8,800 H 1+8,000 H H 1+5,200 H H 2 \leq 50,000$

2. Key indicator A requirement

$A 1+A 2+A A 1 \geq 2$

3. Key indicator $B$ requirement

$A 1+B 1+B 2+B B 1+B B 2+C 2+C 4+C C 1+C C 2+F 1+F 2+$ $F F 1 \geq 2$

4. Key indicator $\mathrm{C}$ requirement

$A A 1+B 1+B B 1+C 1+C 2+C 3+C 4+C 5+C C 1+C C 2 \geq 5$

5. Key indicator $D$ requirement

$C 1+C 2+C C 1+D 1+D D 1+E 1+E E 1+E E 2+E E 3+H 1+H H 2$ $\geq 1$

6. Key indicator E requirement

$E 1+E E 1+E E 2+E E 3+H 1+H H 2 \geq 1$

7. Key indicator $\mathrm{F}$ requirement

$F 1+F 2+F F 1 \geq 2$

8. Key indicator $\mathrm{G}$ requirement

$D 1+D D 1+E E 1+G 1+G 2+G G 1+G G 2+H 1+H H 1+H H 2 \geq 2$

9. Key indicator $\mathrm{H}$ requirement

$D D 1+E E l+H 1+H H 1+H H 2 \geq 1$

10. All variables are $0-1$ variables, i.e. if the variable takes a value 1 , then the activity should be conducted. Else, the activity should not be conducted.

\section{Result}

The solution obtained using Excel QM-Solver shows that only ten activities, namely A1, AA1, B1, C2, C3, CC1, F2, FF1, G2 and HH2 should be conducted in order to fulfil all the KPI requirements. Out of these, four activities are the newly-proposed activities while the remaining six activities are from the old and existing list of activities. The total budget needed is only RM38,830.00. The summary of the result is given in Table5.

Table 5 List of Final Activities to be Conducted

\begin{tabular}{|c|c|c|c|c|c|c|c|c|c|}
\hline \multirow{2}{*}{ Activity } & \multicolumn{7}{|c|}{ Key Indicator } & \multirow{2}{*}{ Cost } \\
\cline { 2 - 11 } & A & B & C & D & E & F & G & H & \\
\hline A1 & $/$ & $/$ & & & & & & & 33,000 \\
\hline AA1 & $/$ & & $/$ & & & & & & 52,000 \\
\hline B1 & & $/$ & $/$ & & & & & & 22,000 \\
\hline C2 & & $/$ & $/$ & $/$ & & & & & 19,080 \\
\hline C3 & & & $/$ & & & & & & 16,500 \\
\hline CC1 & & $/$ & $/$ & $/$ & & & & & 15,000 \\
\hline F2 & & $/$ & & & & $/$ & & & 22,000 \\
\hline FF1 & & $/$ & & & & $/$ & & & 30,000 \\
\hline G2 & & & & & & & $/$ & & 11,000 \\
\hline
\end{tabular}

\begin{tabular}{|c|c|c|c|c|c|c|c|c|c|}
\hline HH2 & & & & & $/$ & & $/$ & $/$ & 44,000 \\
\hline $\begin{array}{c}\text { Total } \\
\text { Needed }\end{array}$ & 2 & 2 & 5 & 1 & 1 & 2 & 2 & 1 & \\
\hline $\begin{array}{c}\text { Total } \\
\text { Selected }\end{array}$ & 2 & 6 & 5 & 2 & 1 & 2 & 2 & 1 & \\
\hline
\end{tabular}

(Note: / indicates the activity can fulfil the key indicator)

\section{Discussion}

Based on the result given in Table 5, it is found that by mapping the activities with the fulfilment of the key indicators as shown in Table 4 , the total number of activities that should be conducted to fulfill all the KPIs has been reduced significantly. From Table 5, the total activities required under indicators $\mathrm{A}, \mathrm{C}, \mathrm{E}, \mathrm{F}, \mathrm{G}$, and $\mathrm{H}$, is two, five, one, two, two, and one, respectively. The activities suggested by the 0-1 IP-model will achieve exactly the minimum requirement for each indicator. On the other hand, the total activities required under indicators B and D are only two and one, respectively. However, the activities suggested by the $0-1$ IP-model can achieve more than the intended requirement, i.e. six and two activities, respectively.

With the reduction in the total number of activities that should be conducted, indirectly, the total budget required also becomes less than the amount spent in the previous year, i.e. only RM38,830.00 for 2017 as opposed to RM60,500.00 in 2016, which is a reduction of almost fifty percent..

\section{Conclusion}

In this paper, we showed how PBMA, with some adjustment, was applied to solve the problem of selecting activities and allocating the budget to fulfil the KPIs set for the student body of U-ABC. The adjustments made on PBMA were on the prioritization strategy which was based on the ranking points set by any university ranking body, and on the 0-1 IP model used to allocate and reallocate the activities to be selected. The result obtained showed that for 2017, only four new activities out of fourteen new suggested activities were included, six old activities were maintained, while a total of ten old activities were discontinued. Although the total amount allocated by the university management is RM50,000.00, only RM38,830.00 would be required in order to fulfil the KPIs set.

The prioritization of the activities was based on MCC only. In reality, when selecting and determining the activities, other factors such as the preference of the students should also be taken into consideration. After all, the success of these activities will depend very much on the support of the students. Thus, for future work, we suggest for this preference factor to be included as well, in the model.

\section{References}

[1] K.J. Smith, A. R. Wateska, M. P. Nowalk, M. Raymund, B. Y. Lee, and R. K. Zimmerman, "Modeling of cost effectiveness of pneumococcal conjugate vaccination strategies in U.S. older adults," American Journal of Preventive Medicine, vol. 44, no. 4, pp. 373-381, 2013.

[2] M. A. Z. Knoll, "The role of behavioral economics and behavioral decision making in American's retirement savings decisions," Society Security Bulletin, vol. 70, no. 4, pp. 1-23, 2010.

[3] P. Brambleby and R. Fordham, "What is PBMA?" 2003, http://www.medicine.ox.ac.uk/bandolier/painres/download/whatis/pb ma.pdf, accessed on 17 April 2016.

[4] P. Brambleby and R. Fordham, "Implementing PBMA," 2003, http://www.medicine.ox.ac.uk/bandolier/painres/download/whatis/ pbmaimp.pdf, accessed on 15 April 2016. 
[5] J. Polisena, K. Tran, and K. Cimon," Home telehealth for chronic obstructive pulmonary disease: a systematic review and metaanalysis," Journal of Telemed Telecare, vol. 16, no. 3, pp. 120-127, 2010.

[6] C. Mitton, F. Dionne, and C. Donaldson, "Managing healthcare budgets in times of austerity: the role of program budgeting and marginal analysis," Applied Health Economics and Health Policy, vol. 12, no. 2, pp. 95-102, 2014

[7] K. E. Hinton, " A Practical Guide to Strategic Planning in Higher Education, Society for College and University Planning," 2012, http://oira.cortland.edu/webpage/planningandassessmentresources/pla nningresources/SCPGuideonPlanning.pdf, accessed on 27 July 2016.

[8] S. Petren, K. Bjerklin, L. A. Marke, and L. Bondemark, "Early correction of posterior crossbite - a cost-minimization analysis," European Journal of Orthodontics, vol. 35, pp. 14-21, 2013.

[9] C. A. F. Drugs and T. I. Health, "Guidelines for the economic evaluation of health technologies: Canada 2006, Ottawa," 2014, http://cadth. ca/media/pdf/186_EconomicGuidelines_e. pdf, accessed on 11 June 2016.

[10] F.G. Uctug and E. Yukseltan, "A linear programming approach to household energy conservation: Efficient allocation of budget," Energy and Buildings, vol. 49, pp. 200-208, 2012. 